\title{
ESPAÇOS DIGITAIS PARA MELHOR APRENDIZAGEM
}

\author{
Digital Spaces for a Better Learning
}

\author{
Christianne Coelho de Souza Reinish Coelho ${ }^{1}$ \\ Francisco Antonio Pereira Fialbo ${ }^{2}$
}

\section{Resumo}

Todos os mundos são mundos virtuais e todos os espaços são ciberespaços. Atualmente, a educação acontece em três diferentes tipos de espaço: o físico, o conceitual e o digital. A metáfora dos Sistemas Complexos Adaptativos SCA - permite-nos entender e ampliar o conceito de agente para qualquer entidade ou ferramenta inteligente capaz de manter um diálogo que promova o aparecimento de emergências, isto é, uma nova configuração que compreende o sistema global composto pelos estudantes, professores, ambiente tecnológico e instituições, e que não pode ser explicado a partir das partes que compõem a ecologia do sistema cognitivo. Este artigo trata do estudo dos agentes e dos espaços envolvidos no processo de ensino e aprendizagem baseado na teoria dos SCA.

Palavras-chave: Educação; Complexidade; Espaços digitais.

\section{Abstract}

All worlds are virtual worlds and all kinds of spaces are cyber spaces. Nowadays, education happens in three different kinds of space, a physical, a conceptual, and a digital space. The metaphor of CAS (Complex Adaptive Systems) allows us to understand and extend the concept of agents to any being or intelligent tool able to sustain a dialogue capable to promote emergencies, that is, new stuff that concerns to the global system composed by students, teachers, technological environment and institutions, and can not be reduced to any individual part of this cognitive ecology system. This paper deals with the determination of the agents and spaces enrolled in the teaching learning process based on CAS theory.

Keywords: Education; Complexity; Virtual spaces.

Professora Doutora da Universidade Federal de Santa Catarina. e-mail: ccsrcoelho@terra.com.br Professor da Universidade Federal de Santa Catarina. e-mail: fapfialho@gmail.com 


\section{Introdução}

Antes de iniciarmos qualquer projeto de software para educação (ensino/aprendizagem), devemos analisar sobre qual teoria pedagógica ele será desenvolvido. Esse aspecto é fundamental para garantir que o produto final será uma ferramenta efetiva para auxiliar a construção do conhecimento.

A maior parte dos softwares educacionais existentes é baseada nas diferentes Teorias Behavioristas, representadas, principalmente, por Skinner, para quem a aprendizagem corresponde à exposição de um comportamento desejado obtido por meio de um "condicionamento operante" (TAROUCO, 1998). Esses softwares apresentam reforços positivos ou negativos às respostas fornecidas pelos estudantes, os quais, segundo os adeptos desta teoria psicológica, seriam capazes de promover mudanças permanentes de comportamento.

Em contrapartida a estas propostas, temos as teorias construtivistas/ construcionistas baseadas, principalmente, nos trabalhos de Piaget (CENTRO DE INFORMAÇÕES MULTIEDUCAÇÃO, 1998) e Vygotsky (1993, 1994). Piaget (1984) afirma que o conhecimento não pode ser concebido como alguma coisa "geneticamente determinada" (teorias inatistas) ou como um "mero resultado de informações percebidas e registradas" (teorias de processamento de informações). O conhecimento resulta de ações e interações entre o sujeito e o ambiente em que vive, em um processo que Piaget, primeiramente, denominava por "Teoria das Equilibrações" para, mais tarde, complementar com sua "Teoria da Abstração Reflexiva".

Qualquer software inspirado nas Teorias Construtivistas/ Construcionistas deve permitir ao estudante o máximo de interação, respeitando, ainda, as representações virtuais que pode estabelecer, ou seja, esquemas de assimilação, se falamos de Piaget, ou zonas de desenvolvimento, se nos suportamos em Vygotsky. Estudantes não devem, apenas, tomar decisões, mas, sobretudo, participar, experimentar e experienciar o conhecimento.

Howard Gardner (1993), em sua "Teoria das Inteligências Múltiplas", afirma que para se atingir o conhecimento, necessitamos coordenar ações originadas de todos os nossos sentidos. Poderíamos introduzir aqui um conceito novo relativo à necessidade de um Design Instrucional Multissensorial. Gardner afirma que o conhecimento é obtido por meio de um sistema de "inteligências" ou habilidades interconectadas que são, em parte, independente e localizadas em diferentes regiões do cérebro, com um padrão de distribuição diferente para cada pessoa e que é fortemente influenciado pela cultura em que se vive.

Estas teorias contrastam com os sistemas de educação tradicionais centrados nas inteligências verbal e matemática. A Teoria das Inteligências Múltiplas implica que os educadores devem estruturar sua apresentação material 
empregando uma forma e um estilo que favoreçam o uso e o desenvolvimento de todas as tais inteligências, principalmente pelo uso da Multimídia e da Realidade Virtual. Os estudantes podem interagir com o computador de diversas maneiras, por meio da visão, redação, leitura, fala, escuta, explorando habilidade musicais, criando metáforas visuais, contando histórias, experiências 3D, resolvendo problemas, usando geometria, resolvendo jogos lógicos, pelo estudo individual ou coletivo, ensinando crianças mais jovens, como fazia Pestallozzi em Yverdun... uma lista quase infinita. O que se discute aqui é a velha dialética entre uma educação voltada para o se ensinar a viver em uma determinada sociedade e a visão Platônica, kantiana de educação, como ferramenta necessária ao desenvolvimento de todo o potencial que o educando é capaz.

Além dos aspectos já mencionados, devemos considerar aspectos sociais e culturais no desenvolvimento de software educacional. A Sociedade da Informação demanda que as pessoas sejam capazes de explorar todas as possibilidades oferecidas pelos computadores. Quando usamos metáforas baseadas no contexto do estudante, é um fator predominante preservar os aspectos históricos e culturais de sua realidade.

\section{Teoria dos sistemas adaptativos complexos}

Para preservar a realidade histórica e cultural, propusemos a utilização da metáfora dos SCA para descrever o contexto dos estudantes. Para Holland (1995), os SCA são, sem exceção, constituídos de um grande número de elementos ativos (agentes) que são diferentes na forma e na capacidade. O comportamento de um grupo de agentes depende das interações de cada componente dentro da rede social que se estabelece. Esse grupo de agentes (agência) pode fazer parte de grupos maiores. Podemos imaginar vários níveis hierárquicos.

Selecionamos quinze conceitos centrais que são a base para a nossa abordagem dos SCA para melhorar a educação (ensino/aprendizagem). Agentes, de uma variedade de tipos, usam suas estratégias, em interações padronizadas, entre si e com artefatos, formando populações de agentes e/ ou estratégias. As interações são afetadas pelo tempo e pelos espaços físico e conceitual em que os agentes estão inseridos. Medidas de desempenho com base em critérios de sucesso dos eventos resultantes direcionam a seleção de agentes e/ou estratégias por meio de cópia e recombinação, mudando, assim, a freqüência dos tipos dentro do sistema. A capacidade interna de autoorganização quanto ao status de adaptação externa do sistema vão determinar a sua evolução. A trajetória de evolução do sistema pode ser representada por um atrator (AXELROD; COHEN, 2000, p. 154, modificado pelos autores). 
De acordo com Axelrod e Cohen (2000), apresentamos alguns dos conceitos da estrutura de referência apresentada:

a) Agente: Exibe algumas características e propriedades, tais como: a habilidade de interagir com seu ambiente, incluindo outros agentes. Um agente pode responder pelo que acontece ao seu redor e pode fazer coisas com mais ou menos propósito, localização - onde os agentes operam; capacidades - como o agente pode afetar o mundo; e memória - que impressões esse agente pode trazer do seu passado. Usualmente pensamos num agente como uma pessoa, tal qual o membro da equipe numa empresa ou um estudante de determinada escola. Considerando esta ampla definição, podemos julgar que uma pessoa não é o único tipo de agente. Uma família, um negócio ou um país inteiro também podem ser um agente. Até um programa de computador interagindo com outros programas pode ser visto como um agente.

b) Estratégia: é um padrão de ação condicional que indica o que fazer em quais circunstâncias e/ou a maneira como um agente responde a sua vizinhança e persegue seus objetivos. Inclui escolha deliberada, no sentido do termo "estratégia de negócios", mas também inclui padrões de resposta que perseguem objetivos com pouca ou nenhuma deliberação.

c) População: é um conjunto de agentes, ou em algumas situações, conjunto de estratégias. Se estivermos interessados em investigar a complexidade, as populações são importantes em três aspectos, como: fonte de possibilidades para se aprender; recipientes para uma nova melhoria encontrada; e parte do nosso ambiente.

d) Tipo: é uma categoria de agente, estratégias, ou artefatos dentro de uma grande população que compartilha algumas características que são detectáveis.

e) Artefato: é um recurso material que tem uma localização definida e pode responder às ações dos agentes.

Neste artigo, focaremos nossa atenção, apenas por limitação do número de páginas, nos conceitos de agente, espaço físico e espaço conceitual. A contribuição mais relevante que faremos será a adição do conceito de espaço digital à estrutura de referência ilustrada pela figura 1 . 


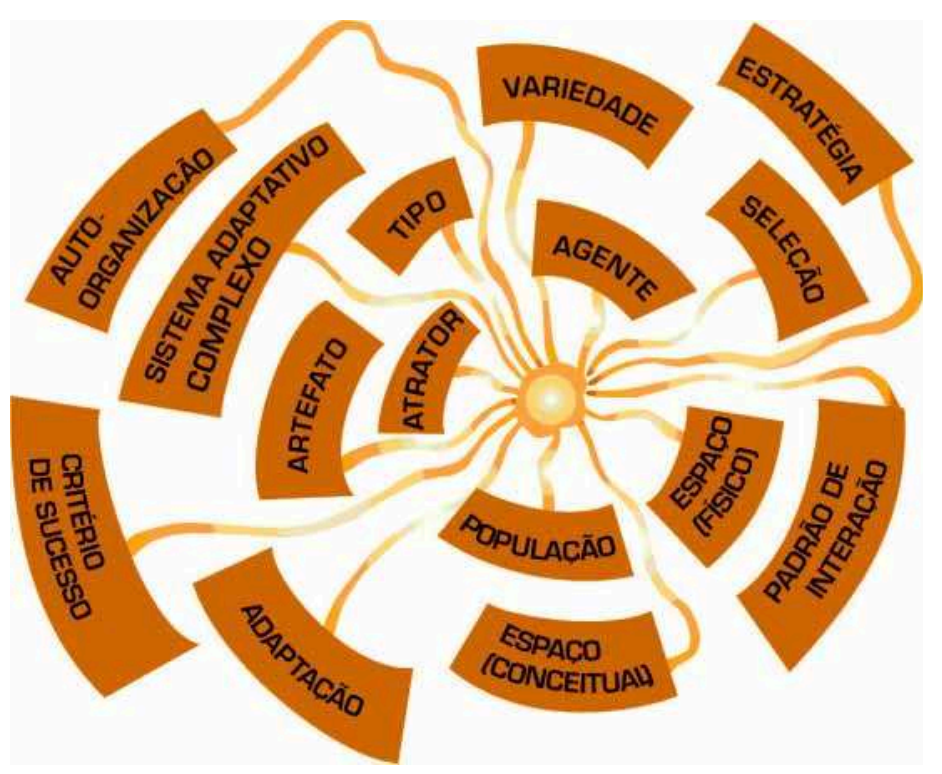

\section{Figura 1 - Conceitos principais relativos aos Sistemas Adaptativos Complexos. Fonte: COELHO, 2001.}

A importância de se estudar os diferentes conceitos de espaço se suporta no trabalho de Axelrod e Cohen (2000), que apontam para o fato de que é útil examinar uma propriedade fundamental de todo o agente, que é o fato de que este está localizado no espaço e no tempo. De alguma maneira, retoma-se o pensamento cartesiano quando Descartes propunha que "O espaço é a forma da experiência ou percepções externas; o tempo é a forma das vivências ou percepções internas. O tempo tem uma posição privilegiada em relação ao espaço, porque é forma da sensibilidade externa e interna, com referência a objetos exteriores e a acontecimentos interiores, abrangendo, assim, a totalidade das vivências possíveis". Quando agentes interagem ou estão colocalizados ou o fazem por meio de alguma tecnologia. Desta forma, podemos dizer que as interações, como os agentes, também estão localizadas no espaço e situadas no tempo.

O espaço físico consiste na localização em um espaço geográfico e em um determinado instante de tempo, de agentes, interações e artefatos. A escola apresenta diferentes tipos de espaços: salas de aula, laboratórios, espaço do recreio, sala de artes, ginásio, etc.; artefatos: computadores, quadro-negro, "flip chart", dispositivos de realidade virtual, etc.; e interações.

O espaço conceitual é a localização dentro de uma determinada taxonomia, ou categorização de tal forma que agentes próximos tenderão a 
interagir com maior probabilidade. Um organograma de uma organização pode ser visto como um mapa conceitual. À medida que nos movemos dentro da hierarquia organizacional, movemo-nos dentro deste espaço conceitual que se caracteriza pela possibilidade de novas formas ou mesmo padrões de interações. Os padrões se modificam mesmo que a pessoa que foi promovida não saia do seu lugar, ou seja, permanece no mesmo espaço físico. De fato, uma maneira útil de se imaginar qualquer organização, escolas em particular, é um projeto deliberado e teleológico de seu espaço conceitual capaz de "organizar" as interações dos agentes e agências (agregados de agentes) com vistas a determinados fins que se pretende atingir.

Um sistema social de castas, ou classes sociais, ou baseada em status, é um bom exemplo para o que seja um espaço conceitual. Outro exemplo é: enquanto as nações podem ser pensadas como regiões localizadas no espaçotempo em que agentes podem estar situados, nacionalidade é algo conceitual. Dentro das escolas, temos professores, supervisores, psicólogos, estudantes, administrativos, todos ocupando algum espaço conceitual específico.

Espaço digital abrange todas as extensões aos espaços físicos e conceituais obtidos pelas possibilidades trazidas pela tecnologia. O espaço digital é a medida de nossa conectividade e sua principal propriedade é a possibilidade de emergências devido a esta conectividade.

Um cuidado especial deve ser dedicado ao projeto de cada um desses espaços e na forma como eles se relacionam entre si. Recentemente, um de nossos alunos nos perguntou sobre qual seria a sala de aula mais avançada e moderna. Trabalhando em uma escola com recursos financeiros razoáveis, havia sido requisitada para buscar esta sala, não importando o preço dela. A conclusão a que chegamos é que não temos resposta para esta pergunta. Enquanto Durkheim preocupava-se com continentes de estabilidade na sociedade como um todo, Moscovivi e Jodelet se debruçavam em ilhas de estabilidade encontráveis nos grupos sociais, nossa ciência se debruça hoje sobre a mudança. O mundo platônico cede espaço ao mundo heraclitiano e o espaço físico, conceitual, digital não é mais sim um eterno devir, uma construção contínua e única, para cada realidade.

Quando pensamos em projetar os espaços digitais e conceituais ideais, a situação é mais complexa. Pedagogos insistem em um design aberto que permita ao aluno uma navegação livre, evitando-se pré-requisitos, disciplinas obrigatórias, etc. Por outro lado, especialistas insistem em núcleos de conhecimento mínimos e supervisão quase militar para garantia de qualidade na educação. Estas discussões são muito recentes e muito trabalho é necessário para que teóricos e práticos em interações dialéticas e dialógicas possam explorar as possibilidades existentes. 


\section{Agentes cognitivos}

O campo da Inteligência Artificial (AI), ao tentar entender o que seria uma entidade inteligente, focou seus estudos sobre o melhor exemplo que temos, nós mesmos, criando teorias e simulando tais teorias em computadores. Um dos objetivos em Ciências da Computação sempre foi obter um máximo de transparência, ou simplicidade, nas interações homens máquinas. Para atingir tal meta, é necessário dotar essas máquinas com estruturas de inteligência similar às que temos.

Desde 1985 que temos uma nova "onda" em AI (MAES, 1998), com novas perspectivas. Esta nova abordagem recebeu muitas denominações, como "pesquisa de agentes autônomos", ou "comportamento baseado em IA", em resposta a algo como "conhecimento baseado em IA", ou ainda "IA bottomup" versus "IA top-down".

Muitas características podem transformar um software em um agente. Podemos mencionar: autonomia, habilidade social, percepção e reação ao ambiente, proatividade e continuidade temporal. Estas são consideradas como uma classificação fraca de agentes (WOOLDRIDGE, 1995).

Em uma classificação forte, agentes devem demonstrar características humanas, tais como emoções, noções de conhecimento, crenças, intenções e obrigações. Todas essas características são necessárias para permitir uma interface inteligente e interativa com nossos estudantes.

Os Agentes Cognitivos devem ser capazes de se mover dentro dos mundos virtuais não apenas para realizar as metas para as quais foram programados, mas sendo capazes, também, de adaptar-se e colaborar com o usuário e outros agentes.

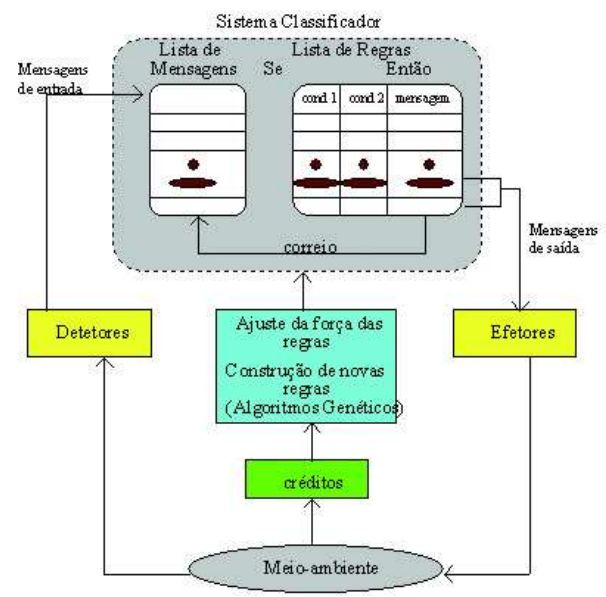

\section{Figura 2 - Agente modelado como um sistema classificador (Adaptado de HOLLAND, 1995)}

Diálogo Educ., Curitiba, v. 7, n. 22, p. 165-174, set./dez. 2007 
Agentes podem ser definidos como algo capaz de perceber, por meiode sentidos, o ambiente em que eles estão inseridos, agindo neste ambiente por meio de efetores. Um exemplo seria a proposta de Holland (1995) relativa a Sistemas Classificadores.

A construção de agentes deve considerar o ambiente no qual este será inserido, dado que o ambiente é quem vai definir o grau de complexidade da percepção que este deverá exibir. O projeto deve especificar, também, a arquitetura do agente, programas e linguagens para sua implementação e a maneira pela qual seu conhecimento será armazenado e recuperado dos bancos de dados.

Dentro da estrutura de referência para os Sistemas Adaptativos Complexos que estamos usando, face as diferenças entre Avatares e Agentes, há algo parecido com o conceito de "actantes" em Latour (2001), embora nem todo artefato possa ser considerado como um "actante".

Podemos ter estudantes interagindo com agentes não humanos (actantes) usados para motivar a aprendizagem, com alguém que eles devem ajudar a se adaptar (agentes dependentes), colegas que estão sempre propondo novos questionamentos (agentes perturbadores), etc.

Nesta metáfora para SCA, os actantes (agentes IA) devem ser considerados como um outro tipo de agente e como qualquer outro tipo de agente sendo capaz de transformar os padrões de interações dentro do sistema educacional.

\section{Conclusão}

Não temos, até agora, teorias de aprendizagem específicas para a Educação a Distância, embora se verifiquem esforços no sentido de adaptar as teorias de Skinner, Gagné, Roger, Ausubel, Egan, Brunner e, principalmente, Piaget e Vygotsky.

Afirmamos que todo mundo é virtual e que todo espaço é cibernético. Afirmamos também que a educação digital deve ser projetada levando em consideração conceitos como os de espaço físico, conceitual e digital.

Qualquer "critério de sucesso" que venhamos a desenvolver acerca da concepção e da implementação da educação digital deve levar em conta a integração desses três espaços. O espaço digital é rico de possibilidade dentro do processo de ensino-aprendizagem sem que, com isso, deva-se diminuir a relevância de um cuidadoso projeto dos espaços físico e conceitual. Ao contrário, o projeto da educação digital deve ser realizado usando a teoria dos Sistemas Adaptativos Complexos. 
Actantes (IA Agentes, mundos virtuais para educação, etc.) devem ser considerados como um novo tipo de agente dentro do sistema educacional, com a capacidade de interagir e modificar os padrões de interações dentro do sistema.

\section{Referências}

AXELROD, R. M.; COHEN, M. D. Harnessing complexity: organizational implications of a scientific frontier. New York: The Free, 2000.

CENTRO DE INFORMAÇÕES MULTIEDUCAÇÃO. Pressupostos da teoria construtivista de Piaget. 1998. Disponível em: <http://www.rio.rj.gov.br/ multirio/cime/ME03/ME01_030.html> . Acesso em: 08 fev. 1999.

COelho, C. C. de S. R. Complexidade e sustentabilidade nas organizações. 2001. Tese (Doutorado em Engenharia de Produção) Programa de Pós-Graduação em Engenharia de Produção, UFSC, 2001.

GARDNER, Howard. Frames of mind: the theory of multiple intelligences. New York: Harper Collins, 1993.

HOLLAND, J. Hidden Order. How adaptation builds complexity. Cambridge: Perseus Books, 1995.

LATOUR, Bruno. A esperança de pandora: Ensaio sobre a realidade dos estudos científicos. Bauru: EDUSC, 2001.

MAES, Pattie. Modeling adaptative autonomous agents. Disponível em: <http://pattie.www.media.mit.edu/people/pattie>. Acesso em: 05 jul. 1998.

PIAGET, Jean. Para onde vai a educação? Rio de Janeiro: José Olympio, 1984.

TAROUCO, L. M. Rockenbach, Aula 12: Comportamentalismo e o computador como máquina de ensinar. 1998. Disponível em: <http://penta2.ufrgs.br/ edu/edu3375/e3375m.htm >. Acesso em: 08 fev. 1999>.

Vygotsky, Lev Semenovictch. Pensamento e linguagem. São Paulo: Martins Fontes, 1993.

A formação social da mente: o desenvolvimento dos processos psicológicos superiores. 5. ed. São Paulo: Martins Fontes, 1994. 
WOOLDRIDGE, Michael Jennings. Nick, intelligent agents theory and practice. 1995. Disponível em: <http://www.doc.mmu.ac.uk/STAFF/mike/ ker95/ker95.html>. Acesso em: 30 set. 1997>.

Recebido: 05 de julho de 2007 Aceito: 17 de agosto de 2007 